\title{
ANÁLISE VISUAL DE ABOBRINHA MINIMAMENTE PROCESSADA EM ATMOSFERA MODIFICADA ATIVA, UMA APLICAÇÃO GEOESTATÍSTICA
}

\author{
Wellington Jorge Cavalcanti Lundgren;; Giovanna Alencar Lundgren²; Juliana Arruda Ramos ${ }^{3}$; Gean \\ Charles Monteiro ${ }^{4}$; Flávia Aparecida de Carvalho Mariano Nasser ${ }^{5}$; Rogério Lopes Vieites 6 . \\ Universidade Federal Rural de Pernambuco, Serra Talhada, Pernambuco, Brasil, \\ wellingtonlundgren@yahoo.com.br \\ Universidade Estadual de São Paulo, Botucatu, São Paulo, Brasil, giolundgren@gmail.com \\ 3Universidade Estadual de São Paulo, Botucatu, São Paulo, Brasil, ju.a.ramos@globo.com \\ 4Universidade Estadual de São Paulo, Botucatu, São Paulo, Brasil, gean.monteiro@yahoo.com.br \\ 5Universidade Estadual de São Paulo, Botucatu, São Paulo, Brasil, flavinha.mariano@gmail.com \\ 6Universidade Estadual de São Paulo, Botucatu, São Paulo, Brasil, rogeriovieites@gmail.com
}

RESUMO: O objetivo deste trabalho foi estudar a possível aplicação da geoestatística em análise visual de abobrinha minimamente processada com atmosfera modificada ativa, que são dados não georeferenciados. A abobrinha passou pelo processamento mínimo em condições normais de higiene e armazenadas em embalagens com diferentes condições de atmosfera: Testemunha atmosfera ambiente (T1), vácuo (T2), $4 \%$ de $\mathrm{O}_{2}+5 \%$ de $\mathrm{CO}_{2}$ (T3), $4 \%$ de $\mathrm{O}_{2}+6 \%$ de $\mathrm{CO}_{2}$ (T4), $4 \%$ de $\mathrm{O}_{2}+7 \%$ de $\mathrm{CO}_{2}$ (T5) e $4 \%$ de $\mathrm{O}_{2}+8 \%$ de $\mathrm{CO}_{2}$ (T6) e analisadas visualmente por avaliadores não selecionados e não treinados por um período de 12 dias com escala hedônica para atratividade e intenção de compra. Foi aplicado a geoestatística com o software GS+. Foi verificada que a intenção de compra apresentou forte dependência espacial. Os tratamentos a $4 \%$ de $\mathrm{O}_{2}+7 \%$ de $\mathrm{CO}_{2}$ (T5) e $4 \%$ de $\mathrm{O}_{2}+8 \%$ de $\mathrm{CO}_{2} 5$ (T6) apresentaram as maiores áreas nos mapas de krigagem para a intenção de compra para os valores de escala hedônica maiores que 4, em todo o período de observação. A maior área no mapa de intenção de compra, após o quarto dia de exposição, para valores da escala hedônica maiores que 4, foi apresentado pelo tratamento 6 .

PALAVRAS CHAVE: Conservação de alimentos, Curcubita moschata, Dependência espacial, Krigagem, Pós-colheita.

\section{VISUAL ANALYSIS OF ZUCCHINI MINIMALLY PROCESSES IN ACTIVE MODIFIED ATMOSPHERE, A GEOSTATISTICAL APPLICATION}

ABSTRACT: The objective of this work was to study the possible application of geostatistics in visual analysis of minimally processed zucchini with active modified atmosphere, which are non - georeferenced data. Ambience atmosphere (T1), vacuum (T2), $4 \% \mathrm{O}_{2}+5 \% \mathrm{CO}_{2}(\mathrm{~T} 3), 4 \% \mathrm{O}_{2}+6 \% \mathrm{Of} \mathrm{CO}_{2}(\mathrm{~T} 4), 4 \%$ of $\mathrm{O}_{2}+7 \%$ of $\mathrm{CO}_{2}$ (T5) and 
$4 \%$ of $\mathrm{O}_{2}+8 \%$ of $\mathrm{CO}_{2}$ (T6) and analyzed visually by unselected and untrained evaluators for a 12-day hedonic scale for Attractiveness and intent to purchase. It was applied geostatistics with GS + software. It was verified that the purchase intention presented a strong spatial dependence. The treatments at $4 \%$ of $\mathrm{O}_{2}+7 \%$ of $\mathrm{CO}_{2}$ ( $\mathrm{T}$ 5) and $4 \%$ of $\mathrm{O}_{2}+8 \%$ of $\mathrm{CO}_{2} 5$ ( $(\mathrm{T}$ ) presented the largest areas in the kriging maps for the purchase intention for the hedonic scale values greater than 4, in Throughout the observation period. The largest area in the intention-to-purchase map, after the fourth day of exposure, for hedonic scale values greater than 4, was presented by treatment 6.

KEYWORDS: Curcubita moschata, Food conservation, Kriging, Postharvest, Space dependence.

\section{ANÁLISIS VISUAL DE CALABAZA MÍNIMAMENTE PROCESADA EN ATMÓSFERA MODIFICADA ACTIVA, UNA APLICACIÓN GEOESTADÍSTICA}

RESUMEN: El objetivo de este trabajo fue estudiar la posible aplicación de la geoestadística en análisis visual de calabaza mínimamente procesada con atmósfera modificada activa, que son datos no georeferenciados. En el caso de las aguas residuales, se observó un aumento en la concentración de agua potable en la zona de estudio de las aguas residuales. (T4), el $4 \%$ de $\mathrm{O}_{2}+7 \%$ de $\mathrm{CO}_{2}$ (T5) y el $4 \%$ de $\mathrm{O}_{2}$ + $8 \%$ de $\mathrm{CO}_{2}$ (T6) y analizadas visualmente por evaluadores no seleccionados y no entrenados por un período de 12 días con una escala hedónica el atractivo y la intención de compra. Se aplicó la geoestadística con el software GS +. Se verificó que la intención de compra presentó fuerte dependencia espacial. Los tratamientos a 4\% de $\mathrm{O}_{2}+7 \%$ de $\mathrm{CO}_{2}$ (T5) y $4 \%$ de $\mathrm{O}_{2}+8 \%$ de $\mathrm{CO}_{2} 5$ (T6) presentaron las áreas más grandes en los mapas de krigado para la intención de compra para los valores de escala hedónica mayores que 4, en todo el período de observación. La mayor área en el mapa de intención de compra, después del cuarto día de exposición, para valores de la escala hedónica mayores que 4, fue presentado por el tratamiento 6.

PALABRAS CLAVE: Conservación de alimentos, Curcubita moschata, Dependencia espacial, Kriging, Post-cosecha. 


\section{INTRODUÇÃO}

A Cucrubita moschata, fruto colhido ainda imaturo, faz parte das oleráceas tipicamente tropicais que vêm ocupando lugar de destaque no mercado, podendo ser usada de diversas maneiras na culinária, o que torna interessante o fornecimento da abobrinha minimamente processada aos consumidores, aumentando assim a praticidade no preparo de refeições.

Os produtos minimamente processados são frutas ou hortaliças que tenham passado por alterações físicas mantendo o estado fresco (MORETTI, 2007) A padronização do produto e menores perdas em póscolheita são algumas das vantagens que podem ser citadas (RUSSO et al. 2012). Contudo são produtos perecíveis, devido ao estresse (cortes) durante o processamento podem apresentar alterações na composição química, produção de metabólitos secundários, perda de massa fresca, aumento no metabolismo e contaminação por microrganismos (LANA et al., 2000).
A modificação da atmosfera, um dos processos utilizados na conservação de produtos minimamente processados, tem como objetivo principal diminuir o metabolismo do produto por meio da redução parcial do $\mathrm{O}_{2}$ e aumento da concentração do $\mathrm{CO}_{2}$ (STEFFENS et al., 2009), o que interfere direto nos processos fisiológico e bioquímicos e reduz a proliferação de microrganismos, resultando no prolongamento da vida de prateleira e, portanto, 0 período de comercialização (NUNES et al., 2005, VIEITES et al., 2014). Para determinar, se a aplicação da atmosfera modificada ativa em abobrinha minimamente processada é comercialmente viável, torna-se necessário uma pesquisa de mercado com a aceitação do produto por seus consumidores.

A geoestatística, segundo Landim (2006) é uma ciência que surgiu nos meados do século passado com os trabalhos de Daniel G. Krige e do estatístico H. S. Sichel e posteriormente 
por Matheron (1962), que Ihe deu rigor matemático.

Várias ciências têm utilizado a geoestatística, Geologia, Engenharia Florestal, Arqueologia, Pesca, Infectologia, Agronomia, Ciências Sociais são algumas das ciências que a utilizam com frequência. A geoestatística tem como principal característica estimar o valor de um atributo em um local geográfico em que o mesmo não foi avaliado.

O objetivo do trabalho é comparar seis diferentes tratamentos em abobrinha minimamente processada utilizando a geoestatística como ferramenta de comparação.

\section{MATERIAL E MÉTODOS}

As Abobrinhas 'Menina Brasileira' provenientes das Centrais de Abastecimento de São Paulo (CEAGESP), SP, foram adquiridas no mercado local de Botucatu - SP, sem defeitos aparentes. Em seguida foram transportadas para o Laboratório de Pós-Colheita de Frutas e Hortaliças, do Departamento de Horticultura da
Faculdade de Ciências Agronômicas (FCA) da Universidade Estadual Paulista "Júlio Mesquita Filho" (UNESP), Botucatu, SP.

O processamento mínimo foi realizado em condições normais de higiene. Os frutos foram lavados em água corrente, para retirada de sujidades, em seguida foram sanificados em solução de hipoclorito de sódio $200 \mathrm{mg} \mathrm{L}^{-1}$, por 10 minutos. Após a imersão no sanificante as abobrinhas foram fatiadas manualmente em sentido transversal, com aproximadamente $5 \mathrm{~mm}$ de espessura, com auxílio de faca afiada de aço inoxidável (FUJITA et al., 2013).

Em seguida as fatias foram sanificadas em solução de hipoclorito de sódio a $50 \mathrm{mg} \mathrm{L}^{-1}$ por 10 minutos. Após a imersão no sanificante, as fatias foram colocadas em escorredor doméstico e lavadas em água corrente para retirada do excesso de cloro, em seguida foram levadas para uma centrífuga doméstica (Consul $\left.{ }^{\circledR}\right)$, por 1 minuto com rotação de 2800 rpm, para retirada do excesso de água. Em 
seguida porções de 150 gramas foram acondicionadas em embalagem plástica de nylon + polietileno transparente de alta barreira de oxigênio $\left(10 \mathrm{~cm}^{3} \mathrm{dia}^{-1}\right)$ e ao vapor de água $\left(5 \mathrm{~m}^{2} \mathrm{dia}^{-1}\right)$, com diferentes condições de atmosfera: Testemunha atmosfera ambiente (T1), vácuo (T2), $4 \%$ de $\mathrm{O}_{2}+5 \%$ de $\mathrm{CO}_{2}(\mathrm{~T} 3), 4 \%$ de $\mathrm{O}_{2}+$ $6 \%$ de $\mathrm{CO}_{2}(\mathrm{~T} 4), 4 \%$ de $\mathrm{O}_{2}+7 \%$ de $\mathrm{CO}_{2}$ (T5) e $4 \%$ de $\mathrm{O}_{2}+8 \%$ de $\mathrm{CO}_{2}$ (T6).

As embalagens foram armazenadas em câmara fria $5 \pm 1^{\circ} \mathrm{C}$ e UR $90 \pm 5 \%$, por 12 dias e a análise visual realizada a cada dois dias da seguinte maneira:

Foram analisadas visualmente por 30 avaliadores escolhidos ao acaso, não treinados, de ambos os sexos, com idade acima de 18 anos recrutados entre funcionários, discentes de graduação e pós-graduação e docentes da Universidade Estadual Paulista Campus Botucatu.

Foi utilizado escala hedônica de 9 pontos para dar notas à atratividade do produto: 1 - desgostei extremamente; 2 - desgostei muito; 3 - desgostei moderadamente; 4 - desgostei ligeiramente; 5 - não gostei/nem desgostei; 6 - gostei ligeiramente; 7 gostei moderadamente; 8 - gostei muito e 9 - gostei muitíssimo. Para determinar a intenção de compra, foi utilizada uma escala de 5 pontos: 1Certamente não compraria; 2provavelmente não compraria; 3talvez compraria/talvez não compraria; 4- provavelmente compraria e 5certamente compraria (DUTCOSKY, 2013).

A geoestatística exige algumas análises exploratórias de seus dados antes de ser utilizada, a primeira é o teste de normalidade do atributo de interesse, segundo Yamamoto e Landim (2015), a normalidade é apenas uma característica desejável. Foi utilizado o teste de normalidade de Kolmogorov-Smirnov

A ferramenta mais importante da geoestatistica segundo Landim (2006) é o semivariograma. A semivariância amostral foi calculada pela função:

$$
Y(h)=\frac{1}{2 N(h)} \sum_{i=1}^{n}\left[Z_{\left(x_{i}\right)}-Z_{\left(x_{i}+h\right)}\right]^{2}
$$


Em que: $Y(h)=$ semivariância amostral, $\mathrm{h}=$ distância, $\mathrm{x}_{\mathrm{i}}=$ ponto $\mathrm{i}, \mathrm{x}_{\mathrm{i}+\mathrm{h}}$ $=$ ponto com distância $\mathrm{h}$ do ponto $\mathrm{x}_{\mathrm{i},} \mathrm{Z}_{(\mathrm{x})}$ $=$ valor do atributo no ponto $\left.x_{i}, Z_{(x i}+h\right)=$ valor do atributo no ponto $x_{(i+h)}$ e $N(h)$ é o número de pontos separados entre si pela distância h.

A análise de tendência verifica se o atributo tem correlação forte com os eixos de coordenadas cartesiana, se a tendência é verificada, ela deve ser retirada dos dados usando-se o ajuste de polinômios de primeiro ou segundo grau em relação aos eixos de coordenadas e o semivariograma deve ser construído com os resíduos. A retirada de tendência segue o procedimento descrito por Davis (1986).

$$
\text { Após a construção do }
$$

semivariograma amostral, um dos

Figura 1. Esquema do semivariograma. vários semivariogramas teóricos existentes deve ser ajustado ao conjunto de pontos. Lundgren (2010) apresenta alguns desses semivariogramas.

Os semivariogramas teóricos possuem três importantes parâmetros, que segundo Landim et al. (2002) são: o alcance (A) que é a distância em que a semivariancia deixa de ter dependência espacial, o patamar (P) que é a semivariância coincidente com o alcance, e o efeito pepita (EP) que é o erro devido a microvariações da distância ou os erros atribuídos a medições dos aparelhos. semivariograma deve possuir o comportamento gráfico na Figura 1.

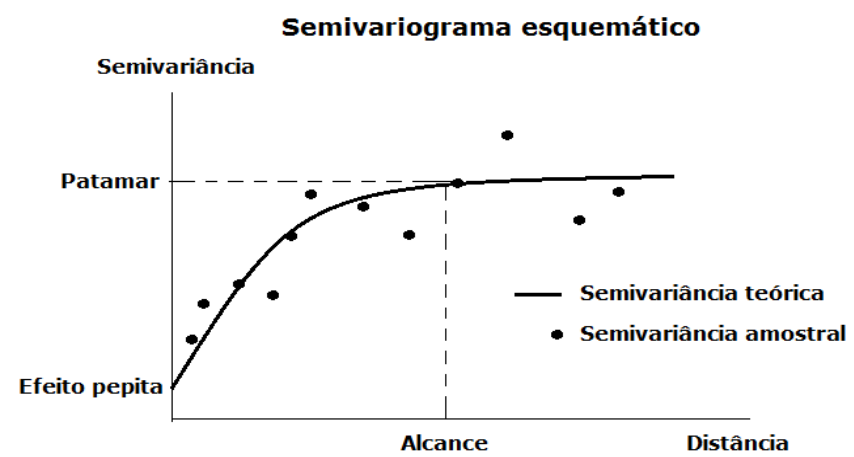


Além da avaliação visual, a existência de dependência espacial foi quantificada utilizando a modificação proposta por Cambardella et al. (1994) que é: DE = 1- (Efeito pepita / Patamar), se DE > 0,75 a dependência será forte, se $0,35<\mathrm{DE} \leq 0,75$ moderada e se $\mathrm{DE}$ $\leq 0,35$ será fraca.

A anisotropia em geoestatística é a característica do atributo de apresentar comportamento de dependência espacial diferenciado para diferentes direções. Yamamoto e Landim (2015) apresentam a maneira de solucionar esse problema, eles sugerem a construção de semivariogramas amostrais em quatro diferentes direções, $0^{\circ}, 45^{\circ}, 90^{\circ}$ e $135^{\circ}$, caso o semivariograma teórico ajustado apresente parâmetros diferente em alguma das direções, estará presente a anisotropia, então, um semivariograma que represente essa característica deve ser construído.

Escolhido o modelo que melhor se ajuste aos dados, um mapa é construído usando-se a krigagem, que é um interpolador que utiliza a informação do atributo de pontos próximos ao ponto em que se deseja estimar o atributo.

A krigagem é um processo de estimação desenvolvido inicialmente pelo Dr. Krige na Africa do Sul para previsão de teores de ouro em minas. A equação de krigagem é segundo Souza et al. (2010):

$$
Z_{x_{0}}=\sum_{i=1}^{n} \lambda_{i} Z_{x_{i}}
$$

Em que: $Z_{x 0}=$ valor do atributo estimado para o ponto $\mathrm{x}_{0}, \lambda_{i}=$ peso atribuído ao atributo da amostra, $Z_{x i}=$ valor do atributo no ponto $x_{i}$.

Os pontos (número de dias que o fruto ficou exposto $x$ valor $d a$ atratividade atribuído pelo avaliador) foram plotados no plano cartesiano e utilizados como se fossem pontos geográficos, o valor do atributo em cada ponto foi o potencial econômico definido como intenção de compra.

O software GS+ foi utilizado para todos os procedimentos geoestatísticos. Para comparação entre os seis tratamentos, foi construído um mapa para cada tratamento, e calculadas as 
áreas aproximadas que cada uma das cinco categorias de intenção de compra.

O mapa foi construído com cinco cores, cada cor representando um valor da escala hedônica de intenção de compra, cada mapa foi subdividido em setecentos e vinte e nove quadrados iguais e a área total do gráfico foi considerada igual a 1 (729 quadrados). As áreas da escala hedônica foram estimadas, contado, o número de quadrados inteiros dentro de cada escala, os quadrados que possuíam duas cores, foram desprezados. $\bigcirc$ valor de cada escala foi calculado pela equação: $V_{E H}=\frac{n q}{729}$,em que: $V_{E H}=$ valor da escala hedônica (intenção de compra), nq = número de quadrados pertencentes a categoria.

Foi considerado o melhor tratamento, o que forneceu maior valor de $\bigvee_{E H}$ para a escala hedônica maior que 3,0 e maior que 4,0.

Para avaliação do erro cometido pela krigagem foram construídos os mapas dos desvios para os mapas de cada um dos tratamentos.

\section{RESULTADOS E DISCUSSÃO}

Nenhum dos tratamentos apresentou distribuição normal dos dados. Os dados foram usados em sua forma original.

A transformação logarítmica foi utilizada por Teixeira et al. (2011) para teores de $\mathrm{CO}_{2}$ em oito diferentes dias. Os dados não apresentaram normalidade, e a transformação logaritmica foi realizada. Dos oito dias, em apenas um, a normalidade não foi obtida com a transformação. Foram construídos mapas por krigagem, e os erros para todos os dias foram aceitáveis, incluindo os dados do dia em que a transformação não funcionou.

Todos os seis tratamentos apresentaram dados com tendência linear para atratividade $\mathrm{x}$ intenção $\mathrm{e}$ nenhuma tendência para dias $\mathrm{x}$ intenção. A correlação positiva da atratividade com o atributo (intenção) era intuitivamente esperada, mas, o tempo não ter correlação negativa com a intenção foi resultado inesperado, o que significa que aparentemente $\mathrm{O}$ tempo não influenciou fortemente na 
intenção de compra, ou seja, todos os tratamentos surtiram algum efeito de durabilidade, efeito desejado por quem utiliza a pós colheita.

Miguel et al., (2009) utilizaram a escala hedônica para intenção de compra da uva italia, eles detectaram um aumento da intenção de compra com o passar dos dias até o décimo quinto dia, deste dia em diante a intenção de compra foi diminuindo até o vigésimo nono dia, quando o experimento foi encerrado.

A existência de tendência nos dados é encontrada em várias pesquisas. Yang et al. (2015) pesquisaram a concentração de Cádmio no munícipio de Wuhan na China e construíram mapas por krigagem representando a concentração do Cd localmente e no tempo, eles encontraram tendência com polinômios de segundo grau tanto para o tempo, como localmente. (VIOLA et al., 2010; LUNDGREN, 2017) encontraram tendência em dados pluviométricos.

Os tratamentos $1,3,5$ e 6 apresentaram comportamentos diferentes para os alcances de seus semivariogramas, quando eles foram construídos na direção de $90^{\circ}$ (direção da atratividade no plano cartesiano "atratividade x dias") confirmando a presença de anisotropia geométrica.

Os tratamentos 2 e 4 não apresentaram anisotropia, os modelos de semivariogramas utilizados, estão apresentados na Tabela 1.

Em todos os tratamentos a dependência espacial (DE) foi alta, e todos os modelos apresentaram patamar, ou seja, foi possível verificar o alcance de cada tratamento.

Na Tabela 2 é possível verificar que o tratamento 5 e 6 obtiveram os maiores valores para o $\bigvee_{E H}$ maior que 4 na escala hedônica da intenção de compra (Valores de intenção de compra com mais intensidade, pois, refletem o potencial econômico do produto), sendo eles 21,39\%, e o tratamento 2 apresentaram a maior quantidade de notas abaixo de 3, para todos os dias de armazenamento.

A partir do $5^{\circ}$ dia de armazenamento (Tabela 3) é possível 
verificar que o tratamento 6 obteve os maiores valores para o $V_{E H}$ maior que 4 na escala hedônica, sendo ele 25,66\%, a partir do $5^{\circ}$ dia de armazenamento, o tratamento 5 não seguiu o mesmo resultado e obteve a maior quantidade de notas entre os valores 2 e 3.0 tratamento 2 teve a maior quantidade de valores entre os valores 1 e 2 .

Tabela 1. Parâmetros dos semivariogramas teóricos.

\begin{tabular}{lcccccc}
\hline \multirow{2}{*}{ Parâmetros } & \multicolumn{5}{c}{ Tratamentos } \\
\cline { 2 - 6 } & 1 & 2 & 3 & 4 & 5 & 6 \\
\hline Tipo & Aniso & Iso & Aniso & Iso & Aniso & Aniso \\
Modelo & Gaussiano & Exponencial & Gaussiano & Gaussiano & Gaussiano & Gaussiano \\
Efeito pepita & 0,378 & 0,484 & 0,180 & 0,277 & 0,137 & 0,173 \\
Patamar & 4,067 & 2,978 & 1,509 & 2,564 & 1,515 & 3,518 \\
Alc. Maior & 19,14 & 31,50 & 11,648 & 11,189 & 11,477 & 8,469 \\
Alc. Menor & 11,31 & 31,50 & 5,122 & 11,189 & 5,698 & 17,684 \\
DE & 0,907 & 0,837 & 0,881 & 0,892 & 0,910 & 0,951 \\
\hline
\end{tabular}

Onde: Aniso = anisotrópico, Iso = Isotrópico, Alc. = alcance. Tratamentos: $1=$ testemunha, 2 = vácuo, $3=4 \%$ de $\mathrm{O}_{2}+5 \%$ de $\mathrm{CO}_{2}, 4=4 \%$ de $\mathrm{O}_{2}+6 \%$ de $\mathrm{CO}_{2}, 5=4 \%$ de $\mathrm{O}_{2}+7 \%$ de $\mathrm{CO}_{2}, 6=4 \%$ de $\mathrm{O}_{2}+$ $8 \%$ de $\mathrm{CO}_{2}$.

Tabela 2. Valores de VEH para cada tratamento e respectiva escala hedônica em todos os dias de armazenamento

\begin{tabular}{ccccccc}
\hline Escala hedônica & Trat 1 & Trat 2 & Trat 3 & Trat 4 & Trat 5 & Trat 6 \\
\hline$>4$ & 0,1838 & 0,1769 & 0,0960 & 0,1563 & 0,2139 & 0,2139 \\
$>3$ & 0,3127 & 0,2866 & 0,4869 & 0,4224 & 0,5240 & 0,3429 \\
$>2$ & 0,1961 & 0,2085 & 0,1344 & 0,1371 & 0,1508 & 0,1673 \\
$>1$ & 0,1262 & 0,1783 & 0,1220 & 0,0932 & 0,0041 & 0,1248 \\
$>0$ & 0,0123 & 0 & 0,0096 & 0,0288 & 0 & 0,0150 \\
\hline
\end{tabular}

Tabela 3. Soma dos valores de VEH para as duas escalas, maior que 4,0 (>4,0) e maior que $3,0(>3,0)$ para cada tratamento Trat = tratamento

\begin{tabular}{ccccccc}
\hline Escala & Trat 1 & Trat 2 & Trat 3 & Trat 4 & Trat 5 & Trat 6 \\
\hline$>4$ & 0,1838 & 0,1769 & 0,0960 & 0,1563 & 0,2139 & 0,2139 \\
$>3$ & 0,3127 & 0,2866 & 0,4869 & 0,4224 & 0,5240 & 0,3429 \\
\hline Soma & 0,4965 & 0,4635 & 0,5829 & 0,5787 & 0,7379 & 0,5568 \\
\hline
\end{tabular}


Pelo critério adotado de escolha do melhor tratamento, a ordem do melhor para o pior seria: tratamento 5, tratamento 3, tratamento 4, tratamento 6, tratamento 1 e tratamento 2. Pesquisa semelhante foi realizada por Nunes et al. (2009) que verificaram parâmetros químicos e visuais na conservação da mandioquinha-salsa usando atmosfera modificada passiva e ativa, ela chegou à conclusão que a atmosfera modificada passiva é suficiente para prolongar a vida de prateleira por 15 dias.
No tratamento 1 (Figura 2) até o $4^{\circ}$ dia, para as pessoas que desgostaram muito do produto, a intenção de compra foi muito baixa, após o $4^{0}$ dia não houve mais as notas mais baixas da escala hedônica, entre os dias 5 e 7,5 o mapa só apresenta as três cores que representam as maiores intenções de compra. Indicando que mesmo para as pessoas que sentiram baixa atratividade visual pelo produto, a intenção de compra apresentou um considerável aumento.

Figura 2. Mapa da krigagem para o tratamento 1 e mapa do desvio padrão da intenção de compra (direita).

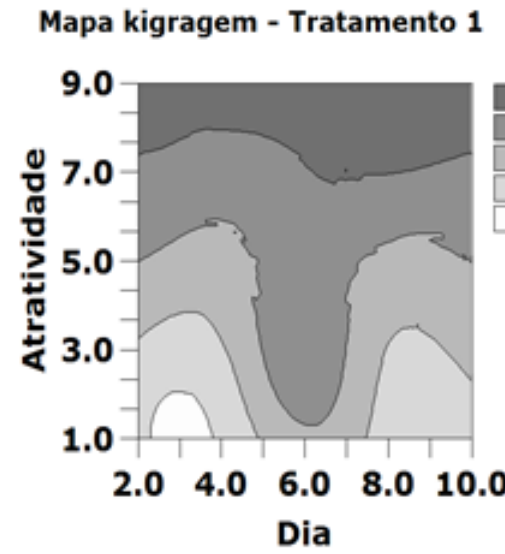

Foi possível perceber um comportamento interessante em relação a intenção de compra no

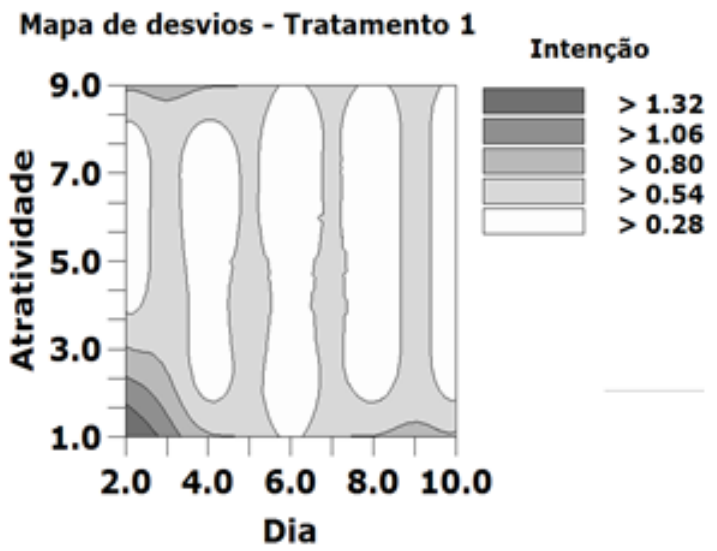

decorrer dos dias, houve um aumento na quantidade de notas maiores que 3 na escala hedônica, inclusive nos 
provadores que classificaram o produto como pouco atrativo a partir do $4^{\circ}$ dia de armazenamento, até o $6^{\circ}$ dia, após o $6^{\circ}$ dia, houve uma queda na intenção de compra dos provadores. $\bigcirc$ que pode ser relacionado com o processo de amadurecimento do fruto, onde o produto que está na sua melhor fase para consumo tende a levar os consumidores a compra e quando começa a entrar em senescência o interesse por seu consumo diminui.

A partir do $5^{\circ}$ dia de armazenamento, os provadores que gostaram moderadamente a muitíssimo do produto aumentaram sua intenção de compra, vindo a diminuir novamente a partir do $8^{\circ}$ dia de armazenamento.

O grau de confiança nos resultados do mapa da intenção de compra da figura 1 pode ser analisado no mapa dos desvios, nota-se que os desvios foram pequenos, quase todo o mapa apresenta valores menores de 0,8 para a intenção de compra, apenas no início da pesquisa e para a pouca atratividade do produto o desvio apresenta pequena área com desvio maior ou igual a 0,8. A geoestatística permite uma análise de erros mais apurada do que a estatística clássica, já que o erro pode ser observado para o local e com diferentes graus de confiança. Muitos autores utilizam a margem de 95\% de confiança do teste de Tukey como um padrão quando trabalham com valores de escala hedônica. (CAVALHEIRO et al., 2001; OLIVEIRA JR et al., 2006; OLIVEIRA et al., 2015).

No tratamento 2 (Figura 3), a vácuo, o comportamento é completamente diferente da testemunha, de uma maneira geral não houve aumento na quantidade de notas satisfatórias ao decorrer do tempo e sim um aumento na quantidade de notas inferiores a 3 e uma diminuição na quantidade de notas superiores a 3. Para os provadores que consideravam o produto atrativo houve um pequeno aumento na intenção de compra entre o $5^{\circ}$ e $8^{\circ}$ dia de armazenamento. A diminuição da intenção de compra se 
torna mais acentuado a partir do $7^{\circ}$ dia de armazenamento entre os provadores que consideraram 0 produto pouco atrativo. Apesar de no geral, haver uma diminuição da intenção de compra no decorrer dos dias, a partir do terceiro dia de armazenamento para as pessoas que gostaram moderadamente a muitíssimo do produto a intenção de compra aumentou.

Figura 3. Mapa da krigagem da intenção de compra do tratamento 2 (esquerda) e mapa do desvio padrão da intenção de compra (direita).

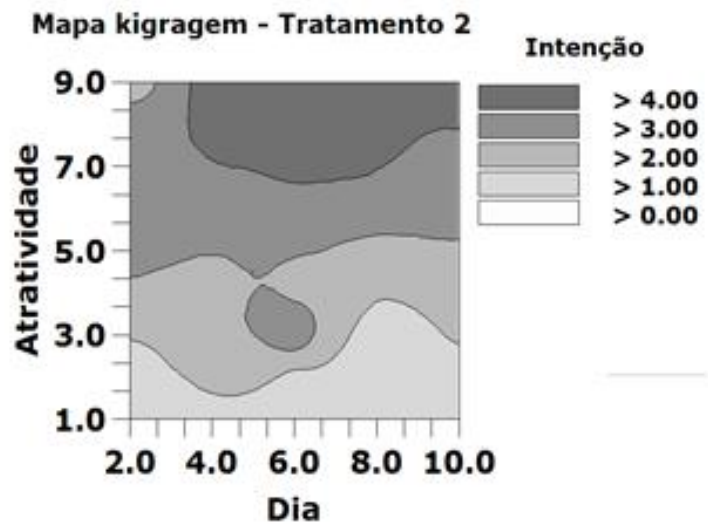

A confiabilidade em geral é alta, porém, para os valores de intenção de compra anteriores ao sétimo dia, e com as notas de atratividade menores que 3 os resultados não apresentam boa confiabilidade com desvios superiores a 0,89 para valores de intenção de compra inferiores a 0,57. Contudo, a área de baixa confiabilidade é pequena em comparação ao mapa como um todo.

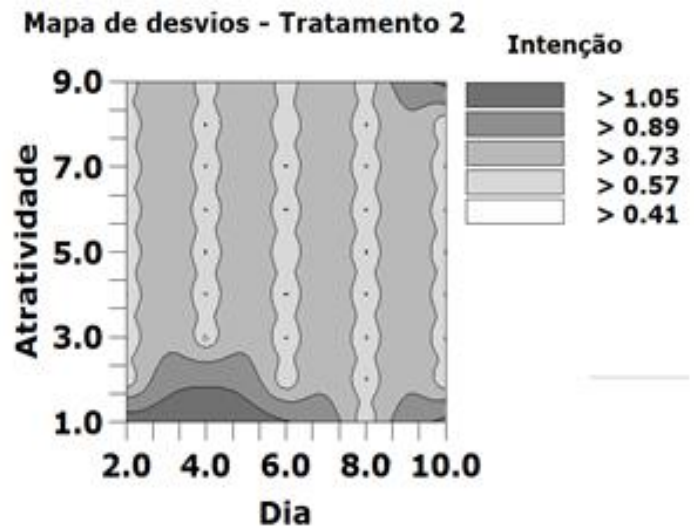

Para o tratamento 3 (Figura 4), entre as pessoas que classificaram o produto como gostei moderadamente à gostei muitíssimo (atratividade entre 7 e 9) a intenção de compra teve um aumento significativo a partir do $7^{\circ}$ dia de armazenamento. Na faixa em que as pessoas não gostaram, nem desgostaram e gostaram ligeiramente a intenção de compra se manteve 
constante durante todo o período de armazenamento.

Para os provadores que desgostaram do produto houve uma alta variação na intenção de compra do decorrer dos dias, entre os dias $3-4$ e
7 - 9, houve um aumento na intenção de compra e entre os dias $2-3,4-7$ e 9 - 10 houve uma diminuição na intenção de compra da abobrinha minimamente processada.

Figura 4. Mapa da krigagem da intenção de compra do tratamento 3 (esquerda) e mapa do desvio padrão da intenção de compra (direita).

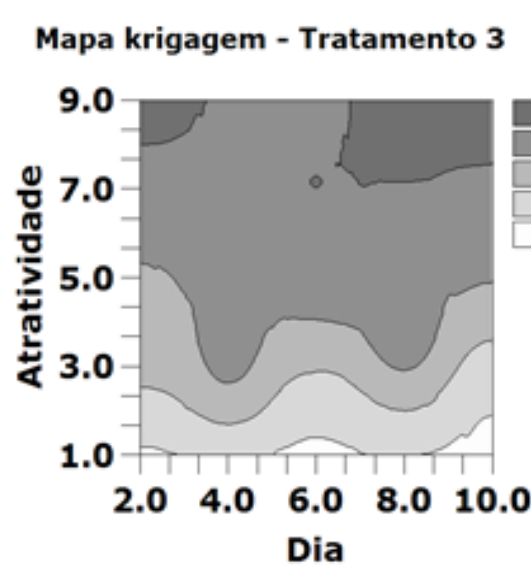

A confiabilidade dos resultados é pequena principalmente na faixa de atratividade menores que 4,0, nessa faixa a intenção de compra se concentrou entre valores menores que 3,0 e o desvio padrão nessa faixa teve uma área considerável em valores entre maior que 0,66 e maior que 1,01.

O tratamento 4 (Figura 5) por todo período de armazenamento teve sua intenção de compra diminuída para

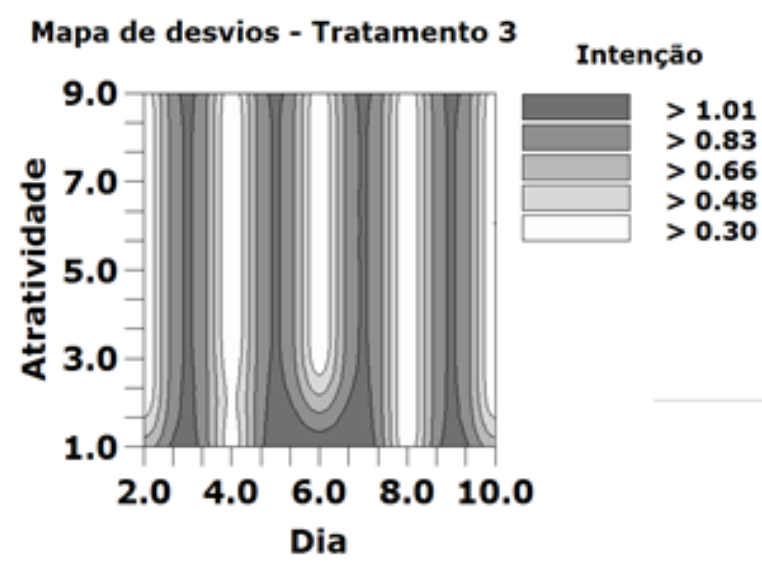

todas as faixas de atratividade do produto, havendo um leve aumento na intenção do $9^{\circ}$ para o $10^{\circ}$ dia, com faixa de intenção com valores maiores que 3,0 .

Esse comportamento pode ter ocorrido porque o tratamento com 6\% de $\mathrm{CO}_{2}$ não conseguiu conservar a abobrinha minimamente processada em todo o período de armazenamento, onde essa 
concentração de $\mathrm{CO}_{2}$ acelerou seu

processo de senescência quando comparado a testemunha. Para os provadores que gostaram ligeiramente do produto comparado a testemunha.

Figura 5. Mapa da krigagem da intenção de compra do tratamento 4 (esquerda) e mapa do desvio padrão da intenção de compra (direita)

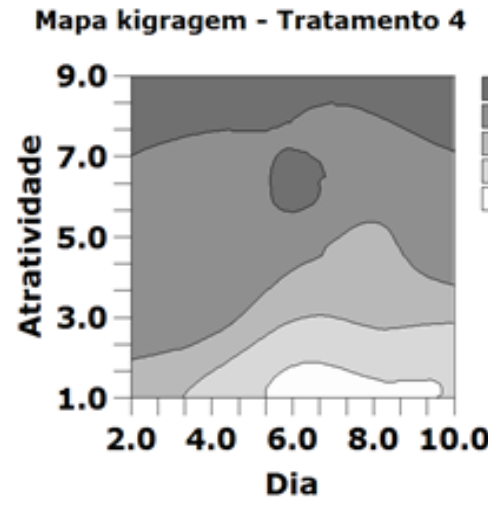

O mapa dos desvios mostra claramente que existe uma alta confiabilidade nos resultados para quase todo o mapa de intenção de compra, semelhantemente ao mapa apresentado nas Figuras 2 e 3 respectivamente os tratamentos 1 e 2 , a baixa confiabilidade foi apenas para antes do terceiro dia e para atratividade inferior a 3,0.

Na faixa de provadores com atratividade inferior a 5,5, com o tratamento 5 (Figura 6), a partir do $6^{\circ}$ dia de armazenamento houve uma alta

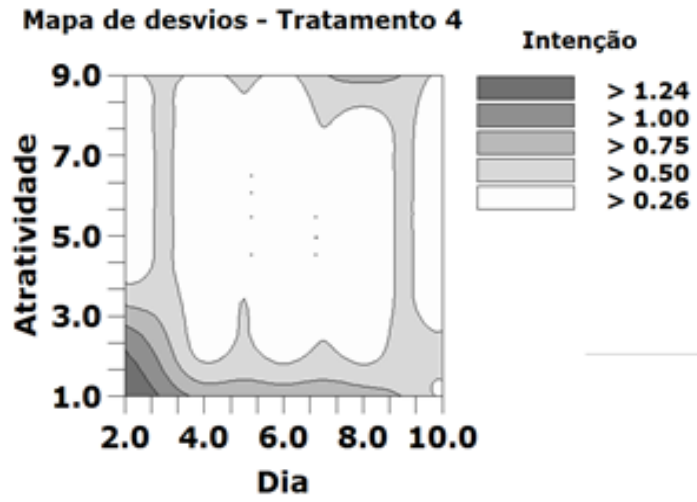

redução na intenção de compra, se mantendo assim até o último dia de armazenamento.

No geral o tratamento 5 apresentou uma alta intenção de compra (valores maiores que 3,0) em quase todo o mapa, tendo apenas uma leve baixa na intenção de compra a partir do sétimo dia e para a atratividade inferior a 5,5.

A confiabilidade dos resultados também boa, grade parte do mapa apresenta desvios inferiores a 0,61, os resultados não foram bons apenas para a faixa da região do mapa onde a 
atratividade foi menor que 3,0. A abobrinha minimamente processada com o tratamento 6 (Figura 7) que foi classificada pelos provadores na atratividade com as notas maiores que 8,0 teve uma alta intenção de compra, onde a partir do $6^{\circ}$ dia armazenamento essa faixa de intenção de compra aumentou abrangendo também os provadores que deram notas 6,0 e 7,0 na atratividade. Já para a faixa de provadores que não gostaram do produto, que deram notas de 1 a 4 para a atratividade, a intenção de compra foi baixa, houve um leve aumento na intenção de compra entre os dias 4 e 6, depois voltaram a diminuir.

Figura 6. Mapa da krigagem da intenção de compra do tratamento 5 (esquerda) e mapa do desvio padrão da intenção de compra (direita).
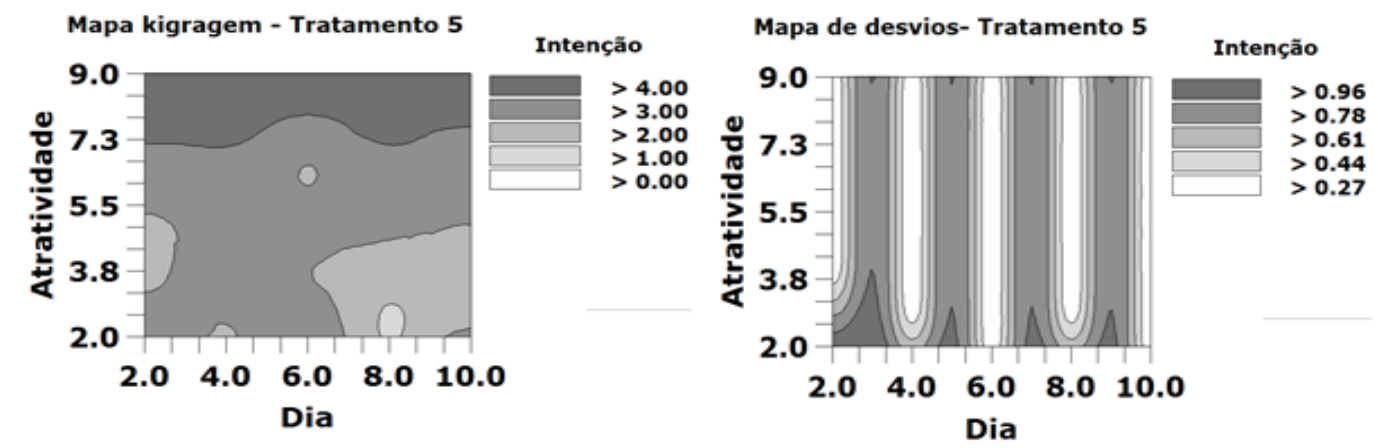

Figura 1. Mapa da krigagem da intenção de compra do tratamento 6 (esquerda) e mapa do desvio padrão da intenção de compra (direita).
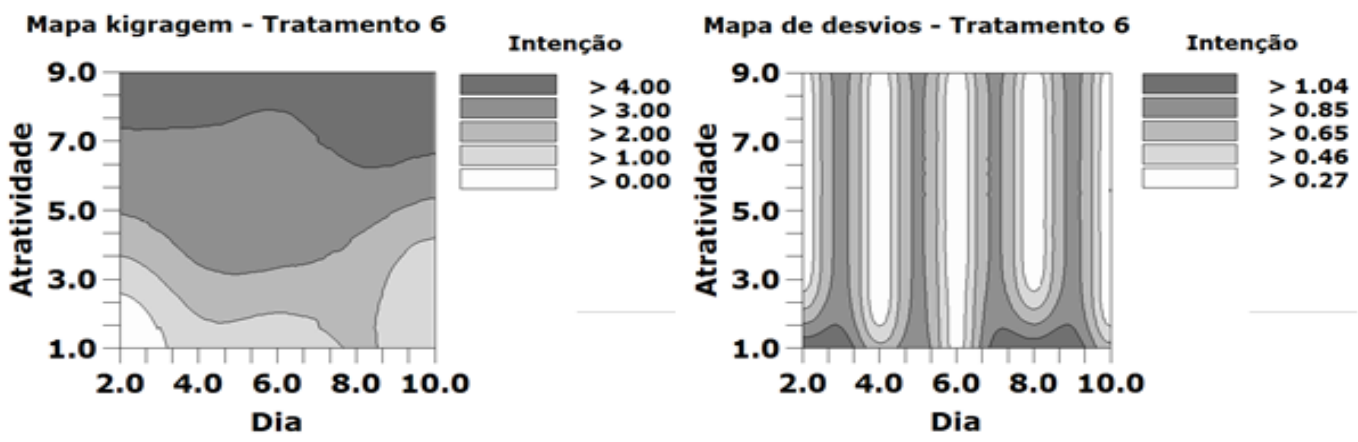
A confiabilidade foi baixa para a faixa de atratividade menor que 2,0 em todos os dias. Para o restante do mapa, em que a maior parte da área é superior a 2,0 nota-se que os desvios nessa área não ultrapassam 0,85 e as faixas que estão entre 0,65 e 0,85 de desvios são pequenas em relação ao todo.

\section{CONCLUSÃO}

A geoestatística pode ser usada como comparativo entre tratamentos em substituição aos testes realizados pela estatística clássica, para análise visual. $\bigcirc$ tratamento com a atmosfera modificada com 4\% $\mathrm{O}_{2}+7 \% \mathrm{CO} 2$ foi considerado o que melhor conservou visualmente mantendo a intenção de compra alta, os demais tratamentos apresentaram a soma das áreas de intenção de compra maior que 3,0 e maior que 4,0 muito próximas, podendo ser considerados iguais para fins práticos.

\section{REFERÊNCIAS}

CAMBARDELLA, C. A.; MOORMAN, T. B.; NOVAK, J. M.; PARKIN, T. B.; KARLEN, D. L.; TURCO, R. F.; KONOPCA, A. E.
Field scale variability of soil properties in Central lowa soils. Soil Science Society of America Journal, v. 58, p. 1501-1511, 1994.

CANTWELL, M. I.; SUSLOW, T. V. Postharvest handling systems: fresh-cut fruits and vegetables. In: KADER, A. A. (Ed.). Postharvest technology of horticultural crops. 3. ed. Davis, California, 2002. cap. 36, p. 445-463.

CAVALHEIRO, S. F. L.; TININIS, C. R. C. S.; TAVANO, O. L.; CUSTÓDIO, M. F.; ROSSI, E. A.; CARDELLO, H. M. A. B. Biscoito sabor chocolate com resíduo de soja, "okara": teste afetivo com crianças em idade pré-escolar. Alimentos e Nutrição Araraquara. v. 12, p.151-162, 2001.

DAVIS, J. C. Statistics and data analysis in geology. 2.ed. New York: John Wiley, 1986.

DUTCOSKY, S. D. Análise sensorial de alimentos. PUCPRESS. Curitiba 2013.

FUJITA, É.; VIEITES, R. L.; DAIUTO, É. R.. Qualidade dos frutos de maná-cubiu minimamente processados submetidos a dois tipos de corte e diferentes concentrações de ácido ascórbico. Revista Iberoamericana de Tecnologia Postcosecha, v. 14, n. 2, p. 238-244, 2013.

KADER, A. A. Modified atmospheres during transport and storage. In: KADER, A. A. (Ed.). Postharvest technology of horticultural crops. 3. ed. Davis, California, 2002. cap. 14, p. 135144. 
LANDIM, P. M. B.; STURARO, J. R.; MONTEIRO, R. C. Krigagem ordinária para situações com tendência regionalizada. DGA, IGCE, UNESP/Rio Claro, Lab. Geomatemática, Texto Didático 06, 12 pp. 2002. Disponível em: $<$

http://www.rc.unesp.br/igce/aplicada/D IDATICOS/LANDIM/tkrigagem.pdf>.

Acesso em:12 mar. 2016.

LANDIM, P. M. B. Sobre geoestatística e mapas. Terræ Didática, v. 2, n. 1, p. 1933, 2006.

LUNDGREN, W. J. C.. Estimativa da Pluviométrica Através das Técnicas da krigagem e cokrigagem no Estado de Sergipe. Revista Brasileira de Geografia Física, v. 10, n. 1, p. 854-865, 2017.

MIGUEL, A. C. A.; DIAS, J. R. P. S.; ALBERTINI, S. SPOTO, M. H. F. Póscolheita de uva "Itália" revestida com filmes à base de alginato de sódio e armazenada sob refrigeração. Ciência e Tecnologia de Alimentos, v. 29, n. 002748, p. 277-282, 2009.

MORETTI, C. L. Panorama do processamento mínimo de frutas e hortaliças. In: MORETTI, C. L. Manual de processamento mínimo de frutas e hortaliças. Brasília: Embrapa Hortaliças, 2007. cap. 4, p. 25-40.

NUNES, F. P., SOARES, N. F. F., GERALDINE, R. M., OLIVEIRA, E., CARNELOSSI, M., PUSCHMANN, R. Efeito de embalagem, temperatura de estocagem e atmosfera modificada na conservação de repolho minimamente processado. Revista Ceres, v. 52, n. 301, p. $435-446,2005$.

NUNES, E. E.; VILAS BOAS; E. V.; XISTO, A. L. R. P.; VILAS BOAS, B. M. Qualidade de mandioquinha-salsa minimamente processada e armazenada sob atmosfera modificada. Ciência Rural, Santa Maria, v. 39, n. 7, p. 2185-2190, 2009.

OLIVEIRA JR, L. F. G.; COELHO, E. M.; COELHO, F. C. Caracterização póscolheita de mamão armazenado em atmosfera modificada. Revista Brasileira de Engenharia Agrícola e Ambiental, $n$. 27, p. 660-664, 2006.

OLIVEIRA, E. N. A., SANTOS, D. C., ROCHA, A. P. T., GOMES, J. P. Microbiological and sensory profile of jelly conventional umbu-cajá. Comunicata Scientiae, v. 6, n. 2, p. 250254, 2015.

RUSSO, V. C.; DAIUTO, E. R.; SANTOS, B. L.; LOZANO, M. G.; VIEITES, R. L.; VIEIRA, M. R. S. Qualidade de abóbora minimamente processada armazenada em atmosfera modificada ativa. Semina: Ciências Agrárias, Londrina, v. 33, n. 3, p. 1071-1084, 2012.

SOUZA, G. S. de; LIMA, H. S. de S.; XAVIER, A. C.; ROCHA, W. S. D. da. Krigagem ordinária e inverso do quadrado da distância aplicados na espacialização de atributos químicos de um argissolo. Scientia agraria, v. 11, n. 1, p. 73-81, 2010.

STEFFENS, C. A.; AMARANTE, C. V. T.; ALVES, E. O.; TANAKA, $H_{\text {.; }}$ BRACKMANN, A. BOTH, $V$. 
Armazenamento de ameixas 'Laetitia' em atmosfera modificada. Ciência Rural, Santa Maria, v. 39, n. 9, p. 24392444, 2009.

TEIXEIRA, D. de B.; PANOSSO, A. R.; PERILLO, L. I.; IAMAGUTI, J. L.; PEREIRA, G. T.; SCALA JÚNIOR, N. L. Krigagem ordinária e simulação sequencial gaussiana na interpolação da emissão de $\mathrm{CO}_{2}$ do solo. Energia na Agricultura, v. 26, n. 3, p. 26-42, 2011.

VIEITES, R. L.; RUSSO, V. C.; DAIUTO, E. R. Qualidade do abacate 'Hass' frigoarmazenado submetido a atmosferas modificadas ativas. Revista Brasileira de Fruticultura, Jaboticabal, $v$. 36, n. 2, p. 329-338, 2014.

VIOLA, M. R.; MELLO, C. R. de; PINTO, D. B. F.; MELLO, J. M. de; ÁVILA, L. F.. Métodos de interpolação espacial para - mapeamento da precipitação pluvial. Revista Brasileira de Engenharia Agricola e Ambiental-Agriambi, v. 14, n. 9, p. 970-978. 2010.

YAMAMOTO, J. K.; LANDIM, P. M. B. Geoestatística: conceitos e aplicações. Oficina de Textos, 2015. $215 p$.

YANG, Y.; WU, J.; CHRISTAKOS, G. Prediction of soil heavy metal distribution using Spatiotemporal Kriging with trend model. Ecological Indicators, v. 56, p. 125-133, 2015. 